\title{
Introduction to HICSS-51 Minitrack on IT and Project Management
}

\author{
Joseph W. Weiss \\ Bentley University \\ Waltham, MA \\ jweiss@,bentley.edu
}

\author{
Jacky Swan \\ The University of Warwick \\ Coventry, UK \\ jacky.swan@wbs.ac.uk
}

Project management and work are important in almost all types of organizations. Recent top project management trends relevant to the IT/Project Management Minitrack include the following: projects that relate to the IoT (Internet of Things) and Big Data, project management methodologies that include an increased emphasis on mobility, agility, flexibility, and teamwork. Other relevant dimensions during all phases of complex projects and programs involve the need to recruit talent, a call for bottomup approaches to align projects with current business objectives; the need for project managers to become more adept at strategy execution as markets become more volatile, and the observation that creating more effective cultures will facilitate effective project planning and implementation.

The Project Management Minitrack is designed to attract papers (and audiences) in the following areas: managing in a multidisciplinary and global technical team environment; using IT- based project management tools and techniques effectively; adopting tools and techniques for managing information system projects; leading in technologybased project organizations; leading and managing internal and external project stakeholders in IT projects.

The papers for this minitrack session include: 1). Virtuoso Project Teams: Beyond High Performance, A Study of the Teaming Success of the Motorola Satellite Communications System IRIDIUM Program, 2). The Evolution of IS Projects in Manufacturing Industries: The Case of Product Lifecycle Management, 3). How Can Steering Committees Manage Change Through Dynamic Capabilities to Increase System Satisfaction? 4). Antecedents and Consequences of Time Pressure in Scrum Projects: Insights from a Qualitative Study; and, 5). Do As You Want Or Do As You Are; Told? Control vs. Autonomy in Agile Software Development Teams.

This year's program presents both scholarly and practitioner research and experience, case study, and theoretical methods of inquiry. 
Page 4814 